\title{
Ideological and Political Education Under the Perspective of Receptive Aesthetics
}

\author{
Jie Zhang, Weifang Zhong \\ School of Marxism, Shihezi University, Shihezi, 832003, China
}

Keywords: receptive aesthetics; ideological and political education; revelation

\begin{abstract}
The effect of ideological and political education can be best embodied by the acceptable behavior of education object. However, the effect of the target education is imperfect, the causes for the issue are complicated due to many reasons, mainly lies in that the object cannot effectively accept it. With the theories of aesthetics taken as the break though point, we will study the acceptance behavior of the educational object in ideological and political education, which attaches important reference significance to broadening of the vision of ideological and political education and improving the effectiveness of ideological and political education of college students.
\end{abstract}

\section{Introduction}

Reception theory or reception aesthetics is a methodology system proposed by German literature aestheticians Hans Robert Jauss and Wolfgang Lser by rethinking about subjects like philosophy and aesthetics from the end of 1960s to the beginning of the 1970s [1]. Reception aesthetics uses phenomenology and hermeneutics as theoretical basis and treats people's reception practice as a foundation. Its core starts from the audience and reception, emphasizes readers' initiative roles in reading and shows receivers' dominant position. Deepening core of reception aesthetics into the field of ideological and political education just involves research on acceptance behaviors happening in the field of ideological and political education. It is reflected by the acceptance subjects' reaction inside ideological and political education and finally internalized and externalized as ideological and ethical standards and behavior characteristics of acceptance subjects. Research on acceptance of educatees is of great practical significance for enhancement and improvement in college students' ideological and political education.

\section{The possibility that ideological and political education consults reception aesthetics theory}

\section{(I) Intersubjectivity of reception aesthetics — theoretical basis of ideological and political} education acceptance

To comprehend the ideological and political education guided by reception aesthetics, we need comprehend a philosophical concept firstly, i.e., intersubjectivity. Intersubjectivity subverts the traditional relationship between subjects and objects, emphasizes relations among subjects, exceeds 'solipsism' dilemma of single subjectivity and walks towards to others' standpoints. In multi-subject relationship, exertion of each subject's subjectivity treats others' creativity, initiative and autonomy as a premise and reaches an agreement by conversational communication and in the form of comprehension, which is specifically reflected by mutual benefit and win-win result, harmonious coexistence and joint development. In the process of the ideological and political education guided by reception aesthetics, educators and educatees exist by common inter-subjects and both are subjects. Besides, they value and respect dominant position of each other and coexist harmoniously and tolerantly. They can not only communicate, talk and exchange with one another but also implement conservation and communication by a new situation and objective world, including ideological and political education, enhance comprehension and identity about objects and accept them based on this.

(II) The necessity that ideological and political education consults reception aesthetics

Consulting 'reception aesthetics' theory for ideological and political education, highlighting educatees' dominant position and thinking about problems from the perspective of educatees are 
helpful for improvement in effect of ideological and political education.

1. Reception theory and reception aesthetics deem that authors, works and readers stay in a process of dynamic contact. In literatures and activities, effect of text communication and acceptance depends on readers instead of authors. Similarly, effect of ideological and political education relies on educatees' acceptance about educational content. Full attention of reception aesthetics theory to acceptance subjects and profound research on the theory provide scientific basis and solid theoretical basis for ideological and political education to discuss acceptance problems of acceptance subjects further. Elaboration about relations among educators, educatees and educational process based on reception aesthetics and reception theory may locate educatees in 'relations' visually, i.e., educatees are 'initiative composition of history' about ideological and political education and participation of educatees is indispensable in the educational process. It is essential to consult reception aesthetics theory in the process of ideological and political education to drive reform and development of ideological and political education and improve effectiveness of ideological and political education.

2. Although there are many similarities between ideological and political education and reception aesthetics in the aspect of acceptance, ideological and political education has its own unique features. Ideological and political education mainly involves acceptance about achievements of value cognition and its primary objective is to make acceptance subjects set up correct world outlook, outlook on life and value and thus from ideal and belief. Ideological and political education is different from those values that can be used directly and have distinct and social and political tendency. Compared with subjects that can be used directly, difficulty in accepting ideological and political education will be higher. Thus, we cannot apply reception aesthetics theory simply or directly but should explore research and application that are appropriate for ideological and political education by its basic concepts and theoretical methods.

\section{Enlightenment of reception aesthetics on ideological and political education}

Acceptance is a behavior about identification of people. In both ideological and political education and reception aesthetics, acceptance is identification whose core is values. After information accumulation, acceptance subjects finally form their own unique good morality and use it to guide their future behaviors by acceptance subjects' comprehension, integration, sublation and creation about acceptance objects. Analysis about enlightenment of the four core concepts 'expectation view', 'aesthetic experience', 'readers' participation' and 'secondary text' in aesthetic experience on acceptance of ideological and political education provides effective theoretical support for acceptance in ideological and political education.

\section{(I) Enlightenment of 'expectation view'}

As one of the core concepts in reception aesthetics theory, expectation view refers to 'an appreciation requirement and appreciation level about literatures, which is formed by integrating readers' previous experience, interestingness, accomplishment and ideal in literary reception activities and expressed as a potential aesthetic expectation in specific reading' [2]. Because of impacts of acceptance subjects' accomplishment and social environment in reception aesthetics, there is thinking set with dual effect in mentality when reading is implemented, i.e., customary orientation expectation and expectation for innovation seeking novelty and difference. The two decides selection and emphasis of recipients' reading and their attitude towards and evaluation on works. Considering how to consult 'expectation view' in ideological and political education, we need analyze acceptance subjects of ideological and political education. College students are a complicated group structure. Their cultural deposits formed in living environment for a long time and diversified values and value orientation make different students have different social demands. It is these features that constitute different 'expectation views' of acceptance subjects in the process of ideological and political education. If ideological and political educators learn educatees' 'expectation view' deeply and master this accurately, their special attention will be aroused more easily and expected educational effect of ideological and political education can be realized. In ideological and political education, acceptance of educatees is based on individuals' cognitive 
structure all the time. For acceptance subjects, they choose acceptance when external knowledge accords with their cognitive structure; when external knowledge does not accord with their cognitive structure, they will choose discrimination, analysis and transformation. While they abandon things, they also absorb something. Finally, they are integrated and formed as new cognitive structure and changed from 'expectation view' to 'expectation changes'. Consequently, ideological and political educators must analyze original 'expectation view' of educatees, guide eduatees to combine new views with old ones and realize 'fusion of horizons'. The stronger educatees' consciousness of demands is, the more internal driving force the acceptance activities will have. Thus, educatees will accept advanced political thought and morality actively so that their thoughts will deposit slowly. Finally, educatees will obtain stable personality psychology and release their potential. Accordingly, the best effect of ideological and political education will be realized.

\section{(II) Enlightenment of 'aesthetic experience'}

In reception aesthetics, 'aesthetic experience' refers to 'direct experience, indirect experience, perceptual experience and rational experience constituted by aesthetic memory and image information that are accumulated by readers when they accept works' [3]. Aesthetic experience has significant impacts on educational objects' acceptance about educational content in ideological and political education. When ideological and political educators educate educational objects, they should consider applying effective communication methods to spread educational content to educational objects firstly. This requires that ideological and political educators can not only learn aesthetic experience of objects but also master it microcosmically. In ideological and political education, aesthetic experience of educational objects is based on the 'expectation view' that deposits in their growing environment, artistic appreciation and communication in social life. Aesthetic experience of educational objects identifies and transforms educational content. When educational content accords with their aesthetic experience and demands, they usually accept it easily. On the contrary, they will resist it. In accordance with 'aesthetic experience' of reception aesthetics, educators should arouse positive factors in 'aesthetic experience' of educatees, devise strategies about 'aesthetic distance between 'aesthetic experience' of reception aesthetics and works' and make it not be separated from reality or spread theory only.

\section{(III) Enlightenment of 'readers' participation'}

Literatures need initiative participation of readers. Reception aesthetics pay special attention to whether readers can participate in works or not. Just as Jauss said, 'Works will enter an expectation view that is changing and reflects continuity only by the medium readers. In the continuity, simple acceptance will be changed into critical comprehension, passive acceptance will be converted into positive acceptance and accepted aesthetical standards will be changed into new literary production that exceeds such standards' [4]. Only readers' initiative effect on literatures can reflect value of works. The enlightenment brought by how to apply 'readers' participation' to reception aesthetics to us is that it is essential to leave blanks and space for thinking. The current society is an economic society with diversified culture. College students' subject consciousness and subject consciousness become increasingly strong. As a result, they do not accept knowledge blindly but need more participation and expression. Educatees' thirst for knowledge is activated and their consciousness of selection about content of ideological and political education and sense of object become more and more obvious. Ideological and political educators should comply with the change, guide college students to participate in ideological and political education, make them express their opinions, comprehension and experience freely and capitalize on the trend.

\section{(IV) Enlightenment of 'secondary text'}

Theory of 'primary text' and 'secondary text' in reception aesthetics provides effective reference for ideological and political education. 'Primary text' refers to literatures without readers' reading, while 'secondary text' involves the ones read by readers. 'Secondary text' means acceptance subjects identify, transform, integrate and recreate 'primary text' based on 'expectation view'. In the process of ideological and political education, 'primary text' may be comprehended as the situation that educators impart theoretical knowledge that has not been read or comprehended by educatees 
and 'secondary text' involves the situation that educatees re-cognize related educational content based on 'primary text'. The key to evaluate effect of college students' acceptance about ideological and political education depends on 'secondary text'. The key affecting acceptance of educational content relates to internal factors like acceptance subjects' cognitive basis, individual demand and value orientation and external factors, such as subjects of education, medium of education and educational environment. Educators should master 'primary text' accurately, analyze and utilize impacts of external and internal factors on acceptance subjects, summarize, give feedback about and guide 'secondary text' of educatees in time and correctly and realize purposes of ideological and political education with comprehension and creation of acceptance subjects.

\section{Effective ways to improve effectiveness of ideological and political education from the perspective of reception aesthetics - establishing educatees' dominant position}

Reception aesthetics deems that key points of evaluation on literatures lie in readers rather than authors. Similarly, evaluation on effectiveness of ideological and political education treats acceptance effect of educatees instead of teaching behaviors of educators as an emphasis. To improve effectiveness of ideological and political education, it is essential to establish educatees' dominant acceptance position and make them accept ideological and political education consciously and independently.

\section{(I) Bilateral interactive harmony}

In the process of college students' traditional ideological and political education, we have tended to single infusion education but ignored educational objects' 'readers' participation' all the time. As independent individuals, educatees own more personal thinking on educational content. It is a pity that educational objects' sense of participation and ability are ignored by educational subjects. Educaitors' impartation and educatees' acceptance form a pair of contradictory obstacles. Difficulty in keeping conservation with educational objects results in low effect of ideological and political education. Educators must make real-time changes and consider educational objects' 'expectation view' and 'aesthetic experience' in the process of educational actively. More importantly, they should focus on educational objects' 'readers' participation', facilitate conversation about ideological and political education into a harmonious and equal method, make educational objects express their opinions and ideas freely without oppression of rights and authority, cultivate and publicize sense of equality in conservation and enable the process of ideological and political education to be free and equal. This will be helpful for active acceptance of educatees.

\section{(II) Establishment of acceptance initiative}

Acceptance initiative means acceptance subjects absorb external information actively and select and create information accordance to their own needs. Initiative and passivity are unity of opposites of perfect humanity. In ideological and political education, students' initiative and passivity are exerted and developed sufficiently. Students' acceptance initiative can be aroused only when their dominant position is established. In accordance with effect of directed expectation and innovative expectation of 'expectation view' in reception aesthetics, it is necessary to make educators feel demands of educatees, start with Reception aesthetics and educate educatees. Edcuatees have had some cultural views and aesthetic taste before accepting education, educators must master key points to ideological and political education, establish eudcatees' dominant position, arouse their acceptance initiative fully, drive educators and educatees reach 'fusion of horizons' and thus improve effect of ideological and political education.

\section{(III) Harmony and unity of difference and diversity}

In the process of ideological and political education, educators must pay attention to educatees' difference and diversity after educatees' dominant position has been established. Each educate has unique growing environment and educational background and different values show different acceptance features. Such features affect their sensitivity to educational content in the process in which they accept ideological and political education as well as their acceptance about educational content. This requires that educators must value educatees' difference and diversity in the process of education, learn and master this deeply and accurately, provide education at a higher level according 
to new needs of educatees and satisfy their demands for development. In this process, it is worth noticing that eudcatees' difference is usually hidden in groups, which requires that educators should improve their sensitivity to observation and provide theoretical education that is appropriate for development of educatees for them. 'Expectation view' of educators and educatees form 'fusion of expectation', achieving realization of perfect expectation of ideological and political education at colleges.

\section{References}

[1] Wang Yuechuan, Hu Jingzhi. Methodology on Aesthetics of Literature and Art, Peking University Press, pp. 333.

[2] Zhu Liyuan. Reception Aesthetics [M]. Shanghai: Shanghai People’s Publishing House, 1989(13).

[3] Xue Yongwu. Draft on Western Aesthetics [M]. Jinan: Shandong Literature and Art Publishing House, 2000.

[4] [German] Hans Robert Jauss. Challenges of History of Literature as Literature Science [A]. Foreign Literature and Art Research Institute of China Academy of Art. Global Art and aesthetics (vol. 9) [C]. Beijing: Culture and Art Press, 1988:1-34. 